\title{
TRANSLATION AS A MEANS OF COMMUNICATION BETWEEN CULTURES AND THE PROBLEM OF FUNCTIONAL ADEQUACY OF POLYSEMIC WORDS ON THE BASIS OF THE ORIGINAL AND ENGLISH VERSIONS OF «THE MARTYRDOM OF THE BLESSED QUEEN SHUSHANIK» BY IAKOB TSURTAVELI
}

\author{
Koniashvili I. O., Georgian Technical University (GTU), Faculty of Engineering, Economics \\ Media Technologies and Social Sciences, Mass Communication Program Ph.D. Student, Tbilisi, \\ Georgia \\ DOI: https://doi.org/10.31435/rsglobal_conf/25012021/7357
}

\begin{abstract}
The present paper deals with the importance of communication and translation as a means of communication between cultures. It also highlights the intra and extra linguistic factors that are significant for translator works and thus, effective communication.

In this respect the paper is an attempt to represent the equivalents of Georgian polysemic words within the frame of paradigms and syntactical functions on the basis of two English versions of Georgian hagiographic text, of the V century AD, The Martyrdom of the Blessed Queen Shushanik by Iakob Tsurtaveli.

The Paper deals with the problem of reference between the notions and subjects, the process of decoding and the reasons for possible simultaneous misconceptions or misunderstanding.

It also outlines the formation of a concept word through the linguistic-stylistic studies of the information by both translators which in turn provides the correct perception of the hagiographic text for the English speaking reader. The research is base don comparative and component analysis.
\end{abstract}

Introduction. Communication is the process of delivery of verbal(oral and written) and nonverbal information in which sender, recipient and information channel are three main features.

Communication process can be classified as 1. Mass-media and Group media. Radio, television and the Internet are the information tools of mass media whilst drama, narrative texts, storytelling, dance and music form group media. One way or other, both mass media and group media mean communication process.

In this case we want to stand out a literary work of hagiography as a means of group media communication in the respect of cross cultural understanding, we mean 'The Martyrdom of The Holy Queen Shushanik' and its English versions.

Cultural globalization

As we have mentioned the translated versions of literary work, we are bound to say that translation means communication between cultures. Namely, one of the first features to consider while finding the right definition of translation, is the fact that communication represents the interaction between the individuals, participants of which are the representatives of linguo-cultural society. Translation as a type of mediation, meanwhile, is not only interlingual but also an intercultural communication tool. In addition, a simple definition of translation can be formulated as follows: 'Translation is a modification of the original text from one language into another.' Thus, translation can be defined as a secondary communication act. In its, turn translation as a secondary communication act is supposed to retain invariant information in the text aiming at the contemporary recipient counting on the maintained balance and adequacy with the perspective of a new, conceptual approach to the text. The presupposition of all this originates in the conceptual approach to the word.

Translation can be defined as an outcome of linguistic-textual work in which a text in one language is given in the context of another. Translation is a cognitive process, that takes place in the mind of translation and social, cross-linguistic and cross-cultural process. Any valid Theory of Translation unambiguously acknowledges these two aspects. Moreover, the existence of Translation Theory is impossible to think of without the recognition of the equivalence as its main role in translating. 
Translating as a linguistic-textual operation is significantly affected by the variety of extralinguistic factors and conditions. Hence the interaction between internal linguistic-textual and external linguistic-contextual factors are the main determiners for translation as a complicated phenomenon Translation methodology involves the sciences of linguistics, text linguistics, information theory and culturology.

Several interactive factors that are worth being considered are as follows:

1. Structural features, potential of expressiveness and the limits of target and source languages.

2. Extra-linguistic complications typical of source and target languages;

3. Text of source language with its linguistic, stylistic and aesthetic traits that belong to the applied norms of the linguo- cultural society of the source language.

4. Linguistic, stylistic and aesthetic norms of target linguo-cultural society;

5. The norms of target language which translator has to familiarize with and exploit.

6. Intertextuality that is responsible for the entirety of the text in the culture of the target language.

7. Traditions, principles, histories and ideologies of the target language linguo-cultural society

8. Short digest provided to the translator while deep in the process by a special or cultural institution;

9. Translator's working conditions;

10. Translator's knowledge, erudition, ethical principles and subjective approach to the translation theory.

11. Target reader's knowledge, erudition, ethical principles and subjective approach to the translator and the translation theory.

Regardless of a number of factors mentioned above, we could give the shortest definition of translation in this manner: 'Translation is a transformation of an original text from one language into another.' But one might misunderstand the word of 'transformation' confusing it with 'changing' the original text. Therefore, translation can be considered as a secondary act of communication. Communicative act in translation is carried out for people or groups of people, but for this, we would miss the importance of communicative act of the original text. In other words, translation is a tool of initial access to another world of knowledge, traditions and beliefs that, but for translation, would have been beyond other cultures due to a linguistic barier. In this respect, translation is often regarded as a means of building up bridges and widening the scope which enables recipients go beyond the limits and share with new culture. That is translation by means of which linguistic-cultural bariers will be possible to overcome. Despite many credits of translation, the facts are transparent - through translation reader can comprehend the already existing message. This 'double nature' heredity means translator's focusing on the adequacy of previous message of the original and that of the product of translation text for the target reader. Such 'double obligatory' approach is the main feature of translation that cannot be ignored.

In accordance with Naida and Taber, the famous theorists of translation, 'Translation is the process during which the stylistic and meaningful transfer of the original information into the target language is bound to occur through the most natural equivalent of the recipients' language. The significance of the present definition is evident when concerning the transfer not only the text and message but poly semantic words as well.'

Before professional translators and scientists there has always emerged one problem: how to translate polysemic words from one language into another with functional adequacy? This is not an easy job not only for those who are fluent in source language and feel confident with the nuances of cross-cultural knowledge, but socio-cultural context as well. literary text is abound with polysemic potential of linguistic unit: polysemy of a word enables a translator to better and freely transfer the author's message through which there forms entire conceptual system, in which word can be realized in different meanings. Thus, the heterogenous nature of a polysemic word gives a creative tint to the text both in source and target languages.

Conceptual studies of polysemic words helps to determine global knowledge and exploit cross-cultural heritage. Such words reveal self-organizing and self-governing power to create a conceptual system. Word that represents a model of real world, becomes the center of an entire system. Moreover, each concept like this in its turn makes its center and each center is incomparable and unique, which directly relates to the top of the semantic pyramid. The effectiveness of this relevance dictates the validity and functional adequacy of a certain word in translated text. 
Main text: Word especially gains its informative potential in old hagiographic text, in which the aim of the author is not self -expression but the expression of a divine word. In this case the author refers to biblical typology. Subsequently, the translator is limited in choice and tries to keep the biblicalhistorical typology within the realm of characteristics of source language. Accordingly, the selforganizing power of word is the main principle while translating which makes a text perfect as a whole.

Every so often a non-adequate word in target language partly falls short of original concept that is the ability of simultaneous realization of polysemy. Consequently, there takes place misconception of original cultural tradition which does not respond to author's message.

To illustrate the postulates mentioned above, we present two English versions of "The Martyrdom of The Blessed Queen Shushanik" by Iakob Tsurtaveli (Iakob from Tsurtavi). This is a Georgian Hagiographic Text which belongs to the $5^{\text {th }}$ century AD. One English version is done by Elizabeth Fuller, the English translator, and the other -by Jumber Cholobargia, Georgian translator.

Donald Rayfield -an English academic and Emeritus Professor of Russian and Georgian at Queen Mary University of London, in his book 'The Literature of Georgia' talks about the translations of Georgian Saints originals regarding them as cultural values and adds that despite their great importance, the earliest literary text that we own, is a formidable hagiographic narrative 'The Passion of Queen Saint Shushanik'(D.R.). From present perspective the narrative describes a woman that revenged on oppressing violator. In addition to the fact that the text is written with great mastery, it is of greatest historical and sociological value.

We only need to add to those words of Rayfield' that the woman was an orthodox Christian

Queen whose husband converted to Zoroastrian faith because of political purposes and wanted his wife and family to do the same but Shushanik resisted and went against his wishes because she was a devoted Christian believer. If she had changed the faith too, that would have shattered the Georgians' faith as well. The husband severely tortured her but Shushanik remained firm and steadfast to the end and in this way she became a contemporary living example for the nation.

Noteworthy, in order to keep the flavor of the Shushanik's contemporary epoch, Georgian translator sensed rightly to use the language of The Bible of James I to preserve the linguistic and stylistic similarity between the source and target languages of two different eras and in this respect to make the "The Martyrdom of The Blessed Queen Shushanik" as a Georgian hagiographic text apprehensible for the English speaking reader.

The Georgian Translator had to make historical- literary interpretation. He thinks that according to the principle of content and thematic synthesis we may talk about the in-variant or sort of direction as a main hypothesis in translation. Truly, translation as a secondary act of communication, is expected to maintain invariant information for contemporary recipient with consistency of balance and adequacy from the perspective of conceptual approach to the text. The precondition of all this is set by the comprehensive conceptual understanding of the word.

The concept word In English version of 'The Martyrdom of The Holy Queen Shushanik' By Jumber Cholobargia, is the word of 'Holy' - Gaobcos (tsminda), which is simultaneously realized in the text with the polysemic informative differentiation. The very word of 'Holy' is used in the title of the text translated by him. - 'The Martyrdom of The Holy Queen Shushanik.' With Elizabeth Fuller such word concept is 'Blessed', right in the title of the text - 'The Martyrdom of The Blessed Queen Shushanik.'

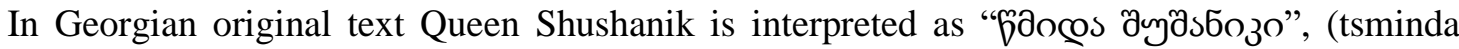

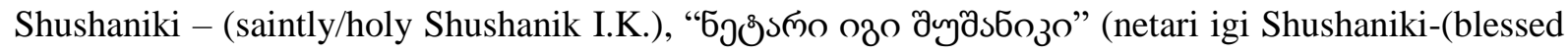
Shushanik I.K.) which is translated in the English version by J. Colobargia as saintly, holy and blessed. These three words are used interchangeably within his English version while with E. Fuller the Queen is mostly called as 'blessed' except for the last paragraphs of her version.

According to the Georgian Explanatory Dictionary by Sulkhan-Saba Orbeliani the word of

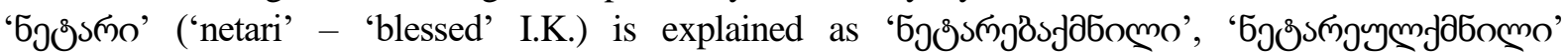

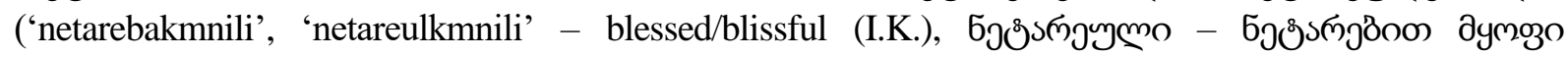
('netareuli' - 'netarebit mkofi' (blissful - in the state of bliss, be blissfully happy I.K.)

The comparative semantic analysis of the given functional adequate equivalents in English is represented as follows: 


\begin{tabular}{|c|c|c|}
\hline Saintly & Holy & Blessed \\
\hline Holy & 1. Sacred & Sacred \\
\hline --------- & 2. consecrated & holy \\
\hline --------- & 3. hallowed & hallowed \\
\hline ---------- & 4. Sanctified & ----------- \\
\hline ---------- & 5. blessed & ------------ \\
\hline ---------- & 6. devoted & ------------ \\
\hline ---------- & 7. set apart & ------------ \\
\hline --------- & 8. raighteous & $\begin{array}{l}\text { Beautified } \\
\text { Blissful }\end{array}$ \\
\hline ----------- & 9. Saintly & --------- \\
\hline 10.devout & 10. devout & ----------- \\
\hline ----------- & 11. spiritual & ----------- \\
\hline 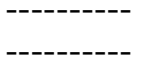 & 12. sinless & \\
\hline ------- & 13. Saint like & --------- \\
\hline
\end{tabular}

All three terms 'Sainltly', 'Holy', 'Blessed' have the same stylistic marker - 'ecclesiastical' or 'churchly' as a religious label. The words of 'Blessed' and 'Saintly' are the common components for the word of 'Holy' or Gaobcos', 'Gaobcosons faobœs' ('tsminda', 'tsmindata tsminda') ('saintly', 'blessed'-(I.K.) whilst the word of 'Holy' itself means both of them along with other additional components with no that much difference. The word of 'Holy' also means: sacred, saint, pious, sinless, divine, peerless. (I.K) From the perspective of semantic meaning the word of 'Holy' represents the way more perfect lexical unit conveying versatile information than the words of 'Sainltly' and 'Blessed,' the interchangeable use of which is completely justified, proper and relevant within the text to describe Shushanik's merits by means of temporal priority system.

For illustration we could have brought in the complete passages directly from the original and translated versions too but this time we prefer to only focus on the concept words from the title of the literary piece:

While developing the plot, along with Shushanik's physical sufferings at the same rate strengthens her spiritual fortitude and, the word 'Blessed' gains those semantic meanings that are combined by its English equivalent 'Holy' and thus, the nucleus becomes directly proportional to the merits, belief and steadfastness of Shushanik. This word represents the intension whose extension is the widest and to which "Blessed', 'Saintly' and 'Saint' are the signs of implication.

Thereupon, during translation after the word 'Martyrdom' the use of 'Holy' to denote the Georgian word ,faocose ('Tsmidai') in the title "The Martyrdom of The Holy Queen Shushanik," by the Georgian translator is irrefutably way more favorable because of its profoundly conceptual understanding than the word 'Blessed' by Fuller in the title as 'The Martyrdom of The Blessed Queen Shushanik.' This is because it can be read in a complex way not only on a linear but also paradigmatic and syntagmatic levels dimensionally.

Conclusions. Within finality, it is the right functional - semantic equivalents that provides a well-organized system of collaboration, compassion and coexistence and that the proper translation is the means of proper communication between cultures. Hence intercultural communication is the adequate mutual understanding between the parts of the communication act.

In the end, when it comes to the translation of different cultural meanings in hagiographic text, reader can recognize historical reality from present time perspective which, in its turn, is the paradigm of formation a new culture.

\section{REFERENCES}

1. Thsurtaveli, Iakob 'THE MARTYRDOM OF THE BLESSED QUEEN SHUSHANIK 'Trnslated by Elisabeth Fuller, obomobo, 'Khelovneba,' 1983

2. Thsurtaveli, Jacob 'THE MARTYRDOM OF THE HOLY QUEEN SHUSHANIK' translated by Jumber

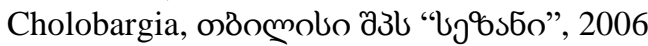

3. Newmark P. 'A textbook of translation' 1988 London ,Prentice Hall

4. Translator as Communicator from www.researchgate.net/publication/307831789_Hatim_B_Mason_I...

5. Nida, E.A. and Taber, C.R. (2004) The Theory and Practice of translation. Shanghai: Shanghai Foreign Language Education Press, p. 24-28

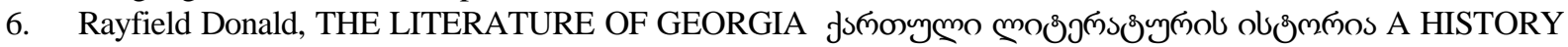
Second revised edition Published in the UK in 2000 by CURZON PRESS England CAUCASUS WORLD. 